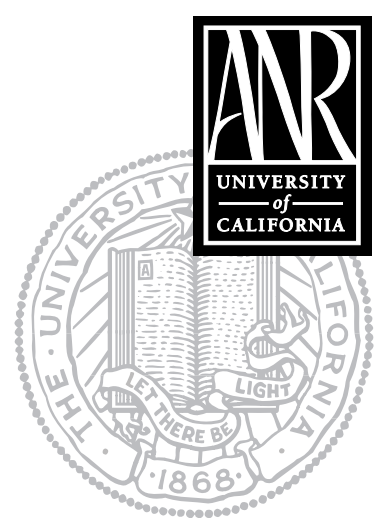

UNIVERSITY OF CALIFORNIA

Division of Agriculture and Natural Resources http://anrcatalog.ucdavis.edu

\title{
Ferrisia gilli: A New Mealybug Pest of Pistachios and Other Deciduous Crops
}

DAVID HAVILAND, University of California Cooperative Extension Farm Advisor, Kern County; ROBERT BEEDE, University of California Cooperative Extension Farm Advisor, Kings and Tulare Counties; KRIS GODFREY, Research Scientist, California Department of Food and Agriculture Biocontrol Program; KENT DAANE, Cooperative Extension Specialist, University of California, Berkeley

\section{INTRODUCTION}

Ferrisia gilli, Gill's mealybug, is a newly described species of mealybug that is spreading throughout pistachio production regions in California (Gullan et al. 2003). In the late 1990s, Gill's mealybug was first found infesting pistachios near the town of Tulare in the southern San Joaquin Valley of California. By 2006 it had spread to at least 3,000 acres (1,214 ha) of pistachios in 11 counties (Butte, Colusa, El Dorado, Fresno, Glenn, Madera, Tulare, Sacramento, Shasta, Stanislaus, and Tehama). Gill's mealybug has also been found, and occasionally caused problems, on almonds, grapes, persimmons, and stone fruits as well as several deciduous ornamentals such as fruitless mulberry.

\section{IDENTIFICATION}

Adult female mealybugs are flat and oval ( 2 to $5 \mathrm{~mm}$, or 0.08 to $0.20 \mathrm{inch}$, in length), and have a pink body covered with white wax. Wax patterns on the body surface give the mealybug a striped appearance. They may also be covered in crystalline filaments (5 to 10 $\mathrm{mm}$, or 0.2 to $0.4 \mathrm{inch}$ ) that have the appearance of long, glassy rods (fig. 1). Adult males, rarely noticed in the field, are smaller than females and have wings (fig. 2). Immature mealybugs, called nymphs, pass through three developmental stages (instars) and look like smaller versions of the adult females.

Gill's mealybug may be confused with the grape mealybug (Pseudococcus maritimus), a nondamaging mealybug that is sometimes found on pistachios. The grape mealybug can be distinguished from Gill's mealybug by its longer tails, filaments around the edge of its body, and lack of long, glassy rods (fig. 3).

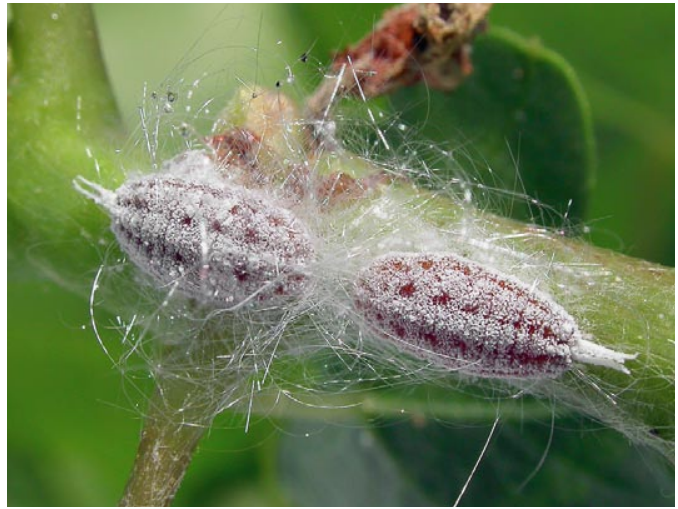

Figure 1. Adult females of Ferrisia gilli have pink bodies and are covered in white wax with bare patches that give the appearance of two stripes down the back. Long, white, glassy rods may also be present, as shown in this photograph.

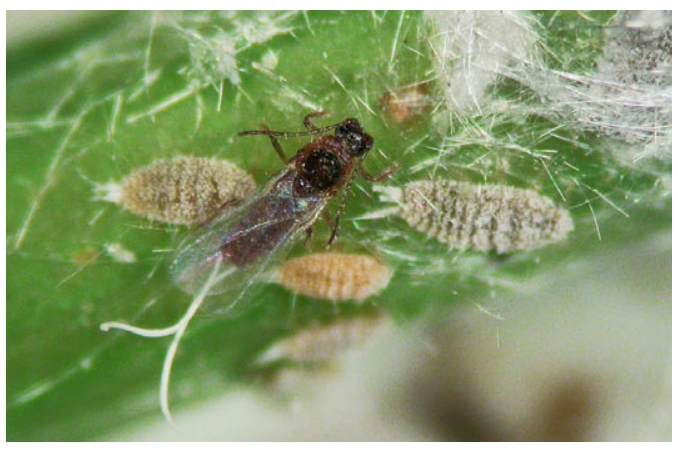

Figure 2. The adult male of Gill's mealybug (center) has one pair of wings and two long tails compared with the wingless immatures and adult females. Adult males are rarely noticed in the field. 


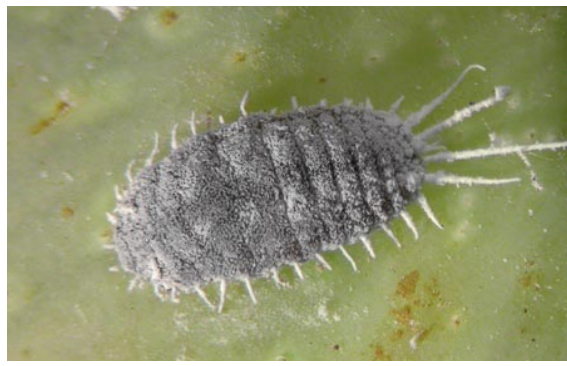

Figure 3. The grape mealybug is sometimes found on pistachios but is not of economic importance. It can be distinguished from Gill's mealybug by its longer tails, lateral filaments, and lack of long, glassy rods.

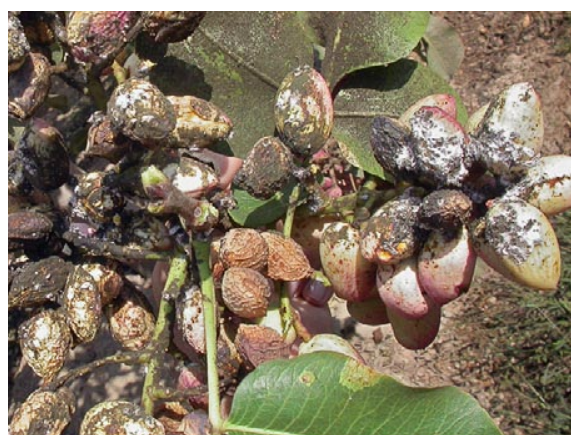

Figure 4. Pistachio clusters can become heavily contaminated with mealybugs, honeydew, and sooty mold.

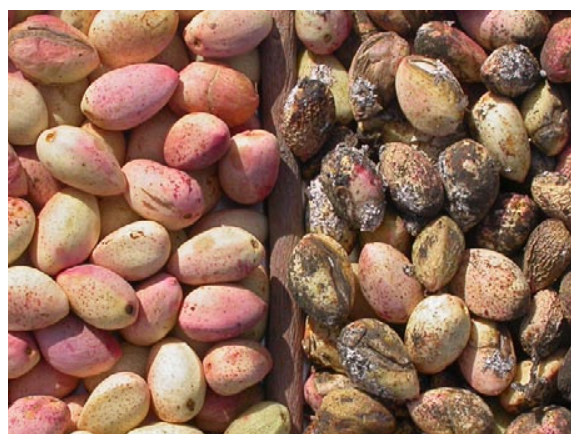

Figure 5. Nuts from uninfested (left) and Gill's mealybug-infested (right) pistachio trees.

\section{DAMAGE}

Mealybugs feed on carbohydrates by sucking plant juices through their strawlike mouthparts. During the late spring and summer they prefer to feed on the rachis and cluster, respectively, where they rob the tree of carbohydrates intended for fruit development (fig. 4). Feeding damage to the pistachio hull also causes shell staining that can demote high-quality split-inshell nuts to less valuable shelling stock (fig. 5). Severe feeding on the rachis or hull can also cause nuts to dry up and shrivel prior to harvest. Many of these nuts do not split and remain in the tree during shaking.

\section{SEASONAL BIOLOGY}

Gill's mealybug has three generations per year in California. After harvest, adult female mealybugs migrate to the main tree scaffolds and trunk where they aggregate and give the wood a white, bearded appearance as if draped in cotton candy (fig. 6). Then they produce crawlers that seek out protected places in cracks and crevices to overwinter. During budbreak, the overwintering nymphs migrate to the swelling buds and begin to feed (fig. 7). They continue feeding at the interface between the previous year's wood and the current year's growth until May, when the overwintering mealybugs reach maturity and move to the rachis (fig. 8). Between late May and mid-June the adult females give live birth to crawlers of the first of two in-season generations that feed on the pistachio hull (fig. 9). The first generation is present from early June through mid-July and the second from mid-July through

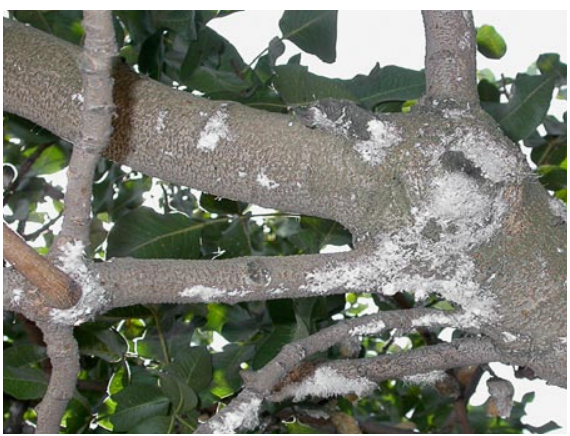

Figure 6. In the fall, Gill's mealybugs aggregate on the trunk and main scaffolds where they give the surface a white, bearded appearance.

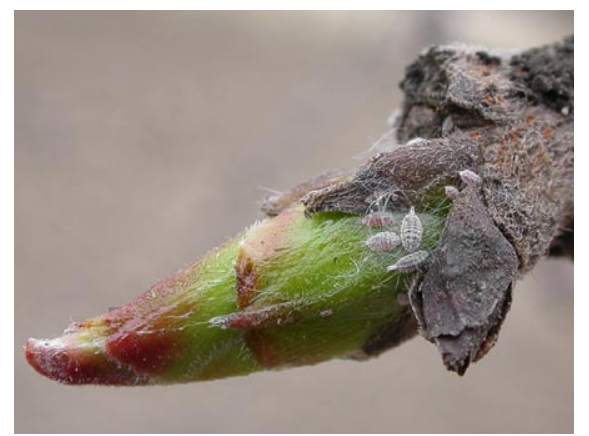

Figure 7. During budbreak the mealybugs migrate to and begin feeding on the swelling bud and developing shoot.

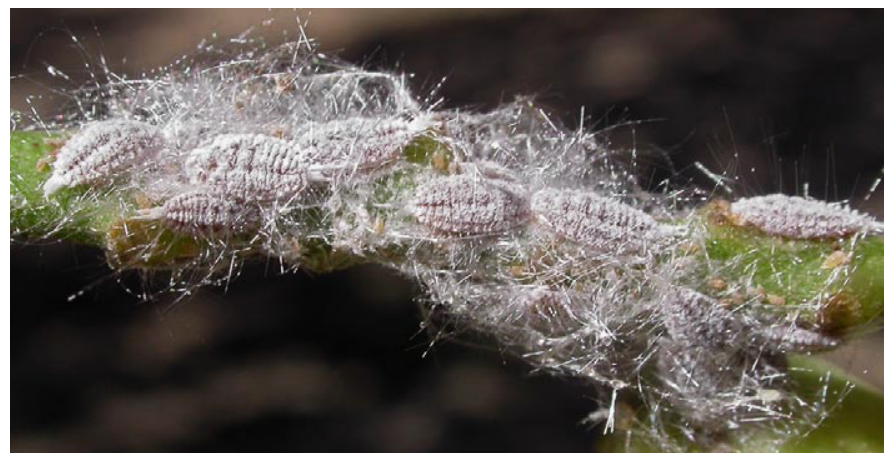

Figure 8. During the late spring, mealybugs prefer to feed on the pistachio rachis, after which they move to the hulls.

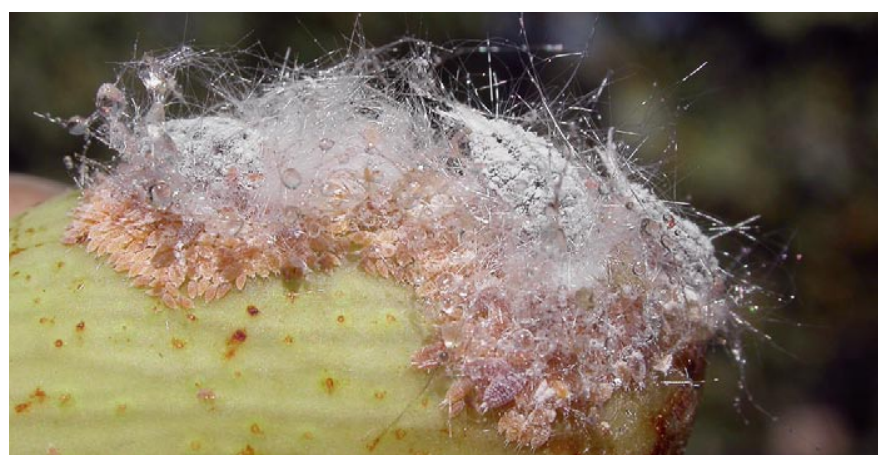

Figure 9. During the summer, adult females of Gill's mealybug produce large numbers of crawlers that aggregate and feed near their mothers. 


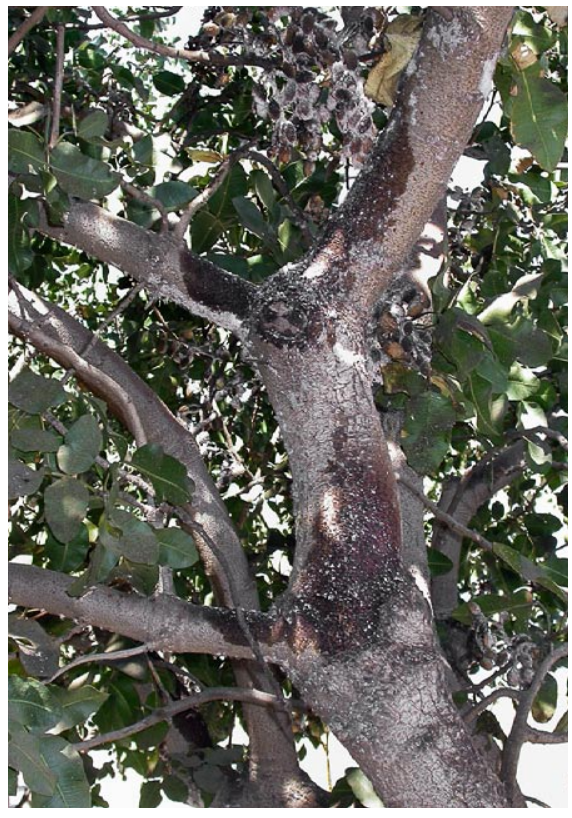

Figure 10. Wet spots from honeydew produced by Gill's mealybugs in pistachio.

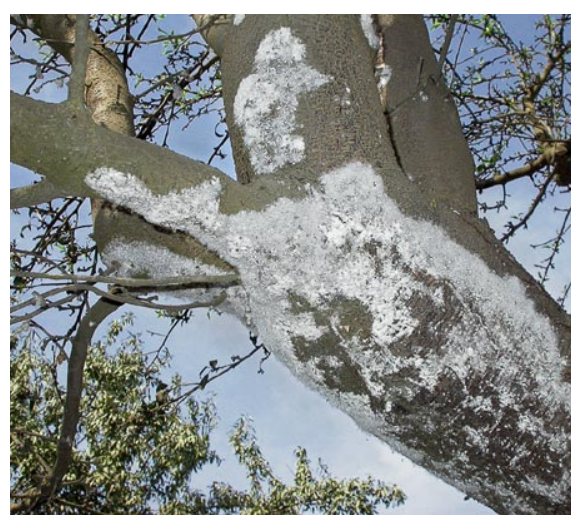

Figure 11. Aggregations of Gill's mealybug on the trunk of one of its alternate hosts, almond.

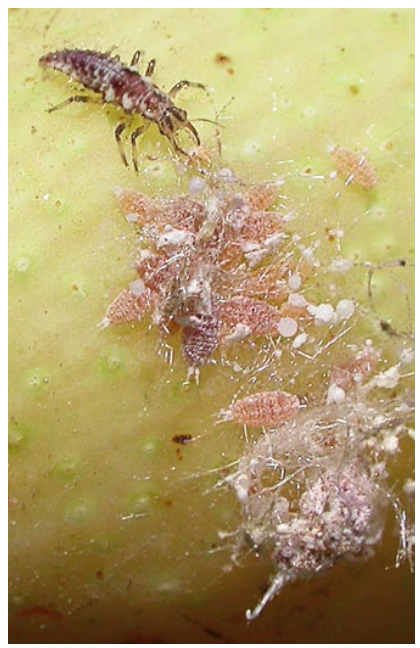

Figure 12. Green lacewing larva feeding on mealybug nymphs. harvest. Whereas the overwintering generation has low survival rates throughout the winter, the two in-season generations are noted for their exponential growth rates such that one mealybug per cluster in May can result in hundreds of mealybugs per cluster at harvest.

\section{FINDING GILL'S MEALYBUG}

\section{Late Summer through Harvest}

Look for wet, shiny, or black areas in the tree canopy (fig. 10). Wet, shiny spots are the result of large amounts of honeydew excreted by the mealybugs, and the black areas are where honeydew has acted as a substrate for the growth of sooty mold. When honeydew or sooty mold is anywhere in the canopy, look for mealybugs within the clusters.

\section{Fall and Early Winter}

Look for white, fuzzy aggregations of mealybugs on the undersides of the main scaffolds, in knotholes, or on the trunk (fig. 11). Even after these adult females have produced offspring and died, their carcasses will remain on the trunk as evidence of an infestation for up to a year. If white aggregations of mealybugs are found, mark the location and return the following spring to determine the need for an in-season insecticide application.

\section{BIOLOGICAL CONTROL}

Several species of predators and parasitoids can suppress Gill's mealybug densities. Predators include green lacewings (fig. 12) and a small brown coccinellid (ladybird) beetle whose larva mimics the appearance of a mealybug (figs. 13 and 14). Parasitoids include wasps in the genera Pseudaphycus, Chrysoplatycerus, and Anagyrus (fig. 15). These parasitoid species have been shown to effectively reduce Gill's mealybug populations on almond, persimmon, and grape crop systems where pyrethrin-based insecticide use is very limited. However, they are rarely found in pistachios where these insecticides are often used for control of true (hemipteran) bugs.

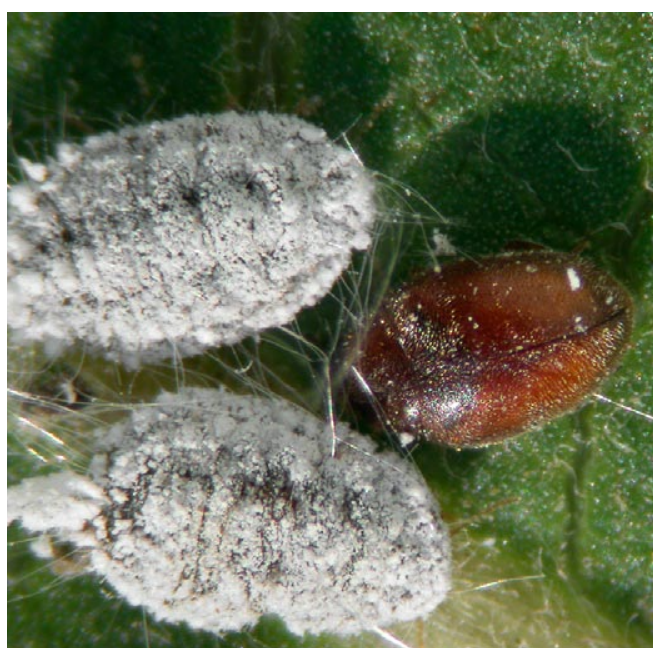

Figure 13. Adult predatory beetle (right) next to two female Gill's mealybugs.

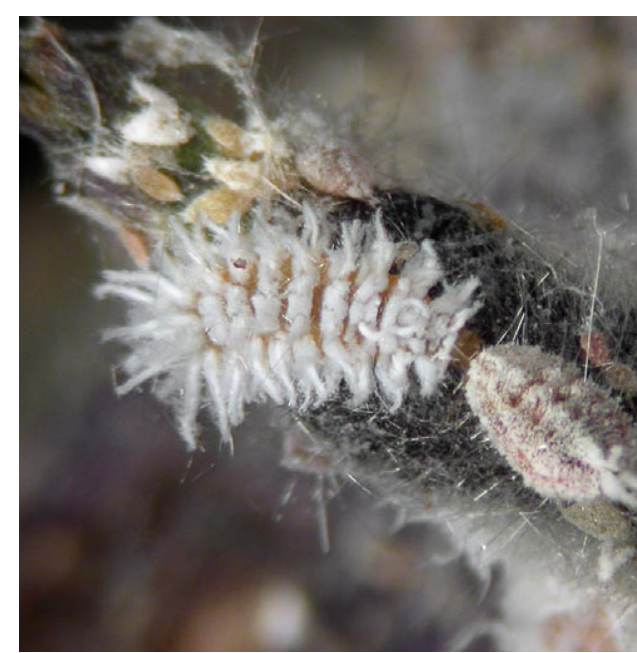

Figure 14. Predatory beetle larva (left) next to a mealybug. 
Mealybugs also have very close associations with ants, which "tend" the mealybugs for their honeydew. One example is the native gray ant (Formica aerata), found in the San Joaquin Valley (fig. 16). It is not certain, however, whether this association with ants is beneficial or harmful to the mealybugs. Certain observations suggest that ants feed on mealybug honeydew and may protect the mealybugs from becoming parasitized; other observations suggest that ants may also feed directly on the mealybugs during certain times of the year.

\section{CHEMICAL CONTROL}

In cases where biological control is insufficient, foliar insecticides can be used to control Gill's mealybug. Optimal application timing is when the majority of the mealybugs are in the crawler stage (first-instar nymph), which occurs from early through mid-June in the San Joaquin Valley. Treatments earlier or later in the season are not as effective, and postharvest treatments have not been evaluated. Ongoing research has documented that insecticides containing buprofezin or acetamiprid are highly effective against the mealybug, and that insecticides containing phosmet or carbaryl can provide partial suppression. A listing of current control options can be found in the UC IPM Pest Management Guidelines for Gill's Mealybug in Pistachios (http://www.ipm.ucdavis.edu).

\section{PREVENTING MEALYBUG SPREAD}

You can help limit the spread of Gill's mealybug by taking the following simple steps:

- Become educated on the mealybug by attending meetings to learn more about its biology and how to control it.

- For orchards not infested, initiate monitoring programs to ensure that pest control advisors, irrigators, pruning crews, and others working in the orchard are trained to recognize and report mealybug infestations.

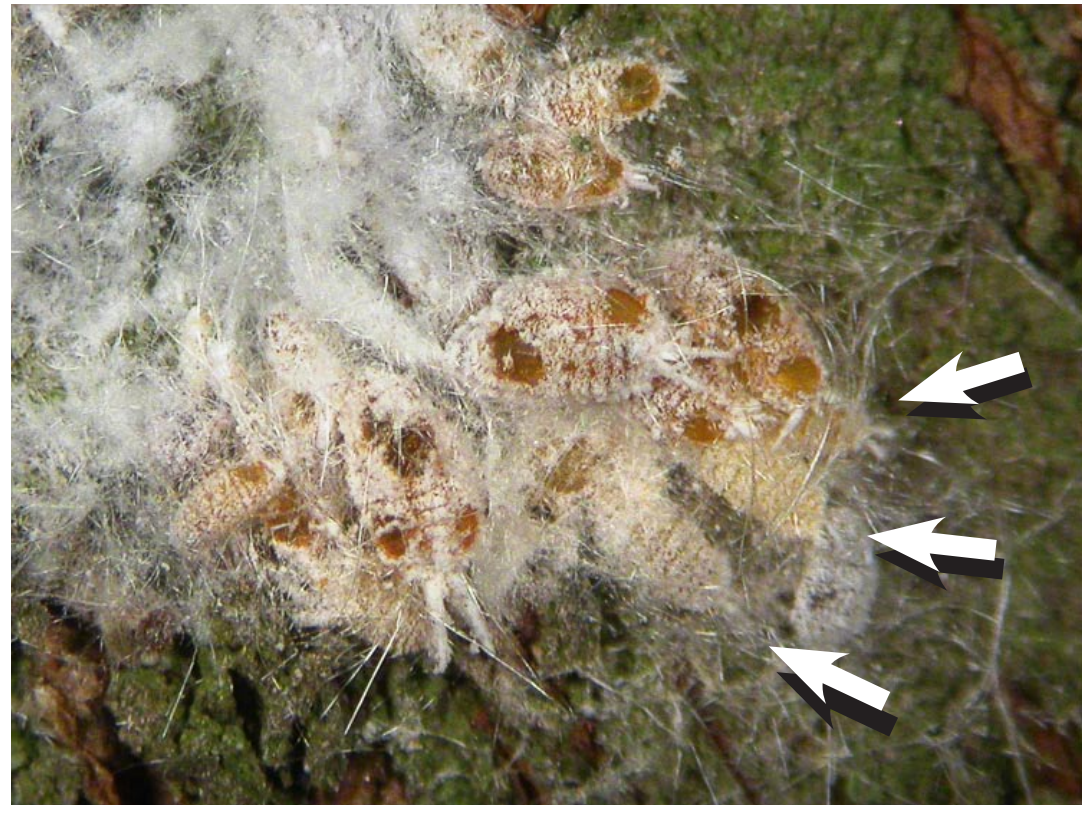

Figure 15. Mealybugs parasitized by one or more wasps will stop feeding, begin to bloat and turn yellow (arrows), and then turn an amber brown color. When parasitoids are fully developed, they chew a round exit hole in the side of the mealybug mummy.

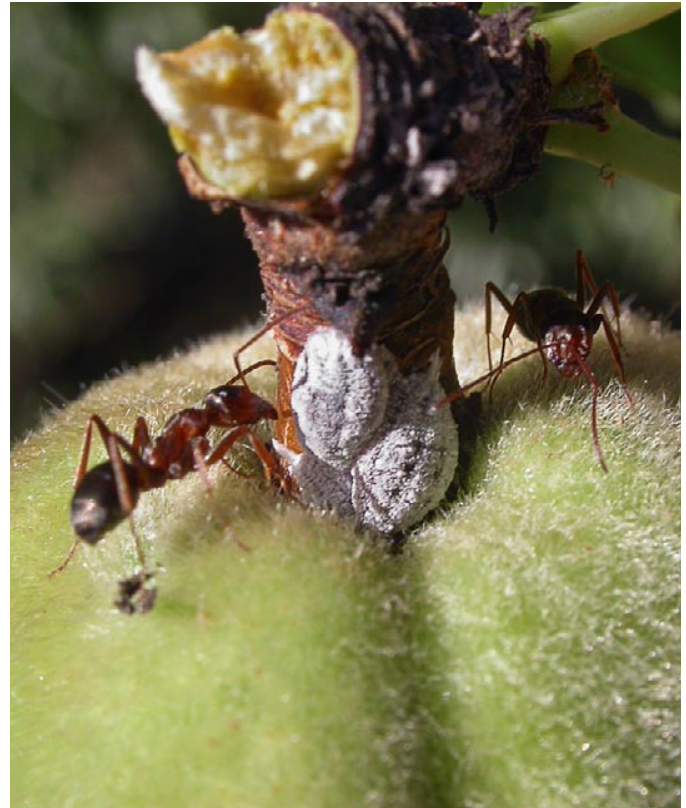

Figure 16. Ants, such as this native gray ant on an almond hull, collect honeydew from mealybugs and protect them from being parasitized. At certain times of the year they may also feed directly on the mealybugs. 
- For infested orchards, ensure that equipment is washed down prior to leaving the site, especially during harvest. Hitchhiking on equipment is the primary means of mealybug spread.

- Ensure that pruning and other field crews do not enter uninfested orchards after working in an area infested with mealybugs.

- When grafting new pistachio orchards, use only budwood collected from locations that do not have mealybug infestations.

\section{SUMMARY}

- Gill's mealybug, Ferrisia gilli, is a newly described species of mealybug that infests pistachios and other deciduous crops and woody plants.

- It feeds on plant juices and can cause significant economic losses by lowering the quality of pistachio nuts.

- Monitor for the mealybug by looking for honeydew and sooty mold during the summer and for white aggregations of mealybugs on the trunk and scaffolds in the fall and winter.

- Biological control organisms are very effective, but only in crops where pyrethrin-based insecticides are not used.

- Where biocontrol is insufficient, mealybug control can be attained by a single in-season application of insecticides such as buprofezin or acetamiprid. Check the UC IPM Pest Management Guidelines for Gill's Mealybug in Pistachios (http://www.ipm.ucdavis.edu) for current chemical control options.

- Prevent mealybug spread by washing down equipment, especially during harvest, prior to leaving orchards known to be infested.

\section{REFERENCES}

Gullan, P. J., D. A. Downie, and S. A. Steffan. 2003. A new pest species of the mealybug genus Ferrisia Fullaway (Hemiptera: Pseudococcidae) from the United States. Annals of the Entomological Society of America 96:723-737.

\section{CREDITS}

All photographs used in this publication were taken by David Haviland. Information included in this publication was made possible through research funding from the California Pistachio Commission and Almond Board of California.

Production of this publication has been supported by a grant from the California Department of Food and Agriculture's Buy California Initiative.

\section{FOR FURTHER INFORMATION}

Additional information about Gill's mealybug can be obtained from your local UCCE Farm Advisor or in the following sources:

University of California IPM Pest Management Guidelines: Pistachio, available for free downloading at the UC IPM Web site, http://www.ipm.ucdavis.edu/PMG/.

Pistachio Production Manual. 2005. 4th ed. Available for purchase from the UC Fruit and Nut Research and Information Center, Department of Plant Sciences, UC Davis. http://fruitsandnuts.ucdavis.edu. 
To order or obtain printed ANR publications and other products, visit the ANR Communication Services online catalog at http://anrcatalog.ucdavis.edu. You can also place orders by mail, phone, or FAX, or request a printed catalog of our products from:

University of California

Agriculture and Natural Resources

Communication Services

6701 San Pablo Avenue, 2nd Floor

Oakland, California 94608-1239

Telephone: (800) 994-8849 or (510) 642-2431

FAX: (510) 643-5470

E-mail inquiries: danrcs@ucdavis.edu

An electronic version of this publication is available on the ANR Communication Services Web site at http://anrcatalog.ucdavis.edu.

Publication 8207

ISBN-13: 978-1-60107-422-5

ISBN-10: 1-60107-422-0

(C) 2006 by the Regents of the University of California, Division of Agriculture and Natural Resources. All rights reserved.

To simplify information, trade names of products have been used. No endorsement of named or illustrated products is intended, nor is criticism implied of similar products that are not mentioned or illustrated.

The University of California prohibits discrimination or harassment of any person on the basis of race, color, national origin, religion, sex, gender identity, pregnancy (including childbirth, and medical conditions related to pregnancy or childbirth), physical or mental disability, medical condition (cancer-related or genetic characteristics), ancestry, marital status, age, sexual orientation, citizenship, or status as a covered veteran (covered veterans are special disabled veterans, recently separated veterans, Vietnam era veterans, or any other veterans who served on active duty during a war or in a campaign or expedition for which a campaign badge has been authorized) in any of its programs or activities. University policy is intended to be consistent with the provisions of applicable State and Federal laws.

Inquiries regarding the University's nondiscrimination policies may be directed to the Affirmative Action/Staff Personnel Services Director, University of California, Agriculture and Natural Resources, 1111 Franklin Street, 6th Floor, Oakland, CA 94607-5201, (510) 987-0096. For a free catalog of other publications, call (800) 994-8849. For help downloading this publication, call (530) 297-4445.

This publication has been anonymously peer reviewed for technical accuracy by University of California scientists and other qualified professionals. This review process was managed by the ANR Associate Editor for Pest Management.

pr-10/06-LR/WFS 